\title{
Historiografi drone: Dari militer hingga sinema
}

\author{
Firdaus Noor \\ Universitas Pembangunan Nasional Veteran Jakarta, Indonesia
}

\begin{abstract}
ABSTRAK
Saat ini drone berkembang menjadi lebih kecil dan lebih cepat, sama dengan kecepatan rana pada kamera. Di dalamnya ada teknologi untuk terbang, kendali nirkabel, kemampuan mengambil gambar, dan kecanggihan warna. Drone mampu terbang rendah tanpa ada gaya tarik ke bawah seperti yang terdapat pada helikopter, drone juga dapat terbang mengitari objek, memiliki kemampuan bermanuver serta dapat mengambil gambar lurus ke depan maupun lurus ke bawah. Pandangan yang dihasilkan drone awalnya merujuk pada pengintaian secara diam-diam yang dikonstruksi saat penggunaan drone dipakai oleh militer yakni untuk mengamati dari atas. Artikel ini berisi penjelajahan tentang perjalanan historis kendaraan udara nirawak yang bisa terbang secara otomatis dengan sistem pengendali di dalamnya, atau populer disebut drone. Tujuan dari artikel ini yaitu untuk mengetahui sejumlah peristiwa penting dalam evolusi kendaraan udara tanpa awak (drone) serta menjelaskan dan memetakan evolusi perkembangan drone dari waktu ke waktu. Kajian ini dilakukan melalui pendekatan sinkronik dan diakronik model Saussure yakni melihat kejadian-kejadian masa lalu yang diurutkan secara kronologis. Dalam penelusuran terkait historiografi drone, penulis membuka peluang untuk melakukan diskusi lebih lanjut melalui simpulan bahwa drone mengajak kita berpikir lebih jauh dari hanya sekadar representasi tapi juga dapat memberikan gambar hidup tentang realitas yang tidak bisa dijangkau oleh pandangan manusia pada umumnya.
\end{abstract}

Kata-Kata Kunci: Historiografi; drone; teknologi; film; sinematografi

\section{Historiography of drone: From military to cinema}

\begin{abstract}
Now the drones are developing smaller and faster, the same as the shutter speed on the camera. Inside is the technology for flying, wireless control, the ability to take pictures, and colour sophistication. Drones can fly low without any downward force like those found on helicopters, and drones can also fly around objects, have the ability to maneuver and take pictures straight ahead or straight down. The view the drone produces originally referred to covert reconnaissance constructed when the military was using drones to observe from above. This article explores the historical journey of unmanned aerial vehicles that can fly automatically with a control system in them, or popularly called drones. The purpose of this article is to find out a number of important events in the evolution of drones and to explain and map the evolution of drone development over time. This study carried out through the the Saussure model synchronic and diachronic approaches, that is looking at past events sorted chronologically. In tracing the historiography of the drone, the author opens the opportunity for further discussion through the conclusion that the drone invites us to think beyond mere representations but can also provide a vivid image of reality that cannot be reached by human view in general.
\end{abstract}

Keywords: Historiography; drone; technology; film; cinematography

Korespondensi: Firdaus Noor, M.I.Kom. Universitas Pembangunan Nasional Veteran Jakarta. Jalan Raya Fatmawati No. 1, Pondok Labu, Jakarta Selatan.Email: firdausnoor@upnvj.ac.id 


\section{PENDAHULUAN}

Upaya manusia untuk bisa terbang telah diuji sejak awal sejarah peradaban manusia itu sendiri. Keinginan untuk terbang telah dicoba sejak jaman kuno oleh seorang arsitek juga seniman dari Yunani; Dedal dan Icarus, kemudian dilanjutkan proyek anatomi burung oleh seorang ilmuwan popular pada masa Renaissance, Leonardo da Vinci 14521519 setelah itu proyek eksperimen berupa parasut oleh Montgolfer pada tahun 1783. Tidak berhenti di sini, upaya berlanjut dengan keinginan mencipta pesawat nirawak yang dapat diterbangkan lebih mudah dan lebih ringan oleh Santos-Dumont pada tahun 1899 dan Zeppelin
1900-1909, serta pesawat nirawak yang dapat dikontrol dari jarak jauh oleh Otto Lilienthal 1890-1896, terus dikembangkan secara pesat pada saat Perang Dunia I dan Perang Dunia II.

Kendaraan udara tanpa awak dikenal dengan banyak nama dan akronim sepanjang sejarah, yaitu; Drone, RPV (Remotely Piloted Vehicle), UAV (Unmanned Aerial Vehicle), UCAV (Uninhabited Combat Aerial Vehicle), FVO (Organic Aerial Vehicle), UCAV/S (Uhinhabited Combat Aircraft Vehicles/ System), RPA (Remotely Piloted Aircraft), RPH (Remotely Piloted Helicopter), Aerial Robotics, dan MAV (Micro Aerial Vehicle).

Drone lebih dikenal sebagai sistem udara

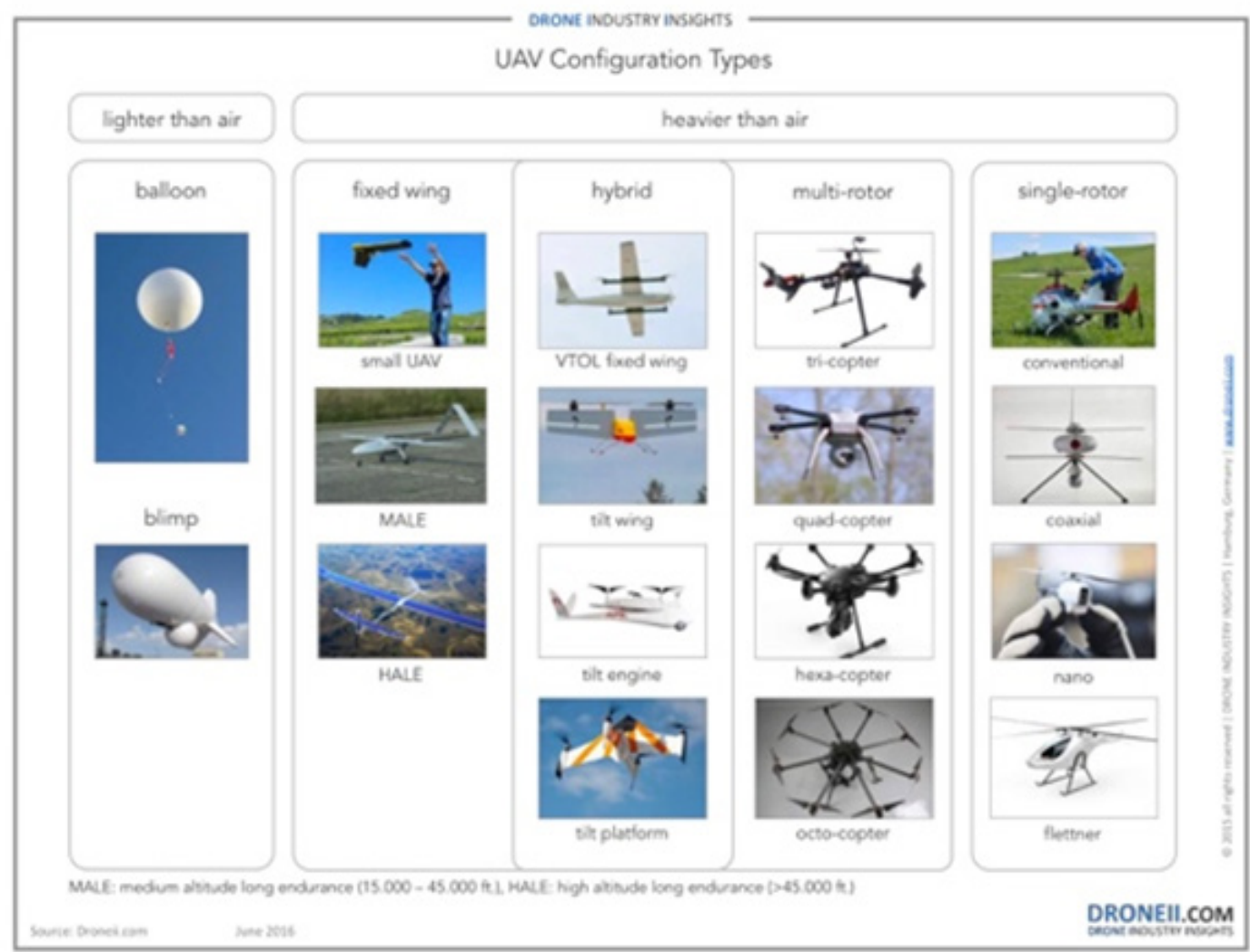

Sumber: Droneii.com, 2019 
tak berawak atau sistem pesawat jarak jauh, yang telah membuat begitu banyak perubahan, pada awalnya drone hanya difungsikan sebagai pengawasan dalam militer.

Dalam beberapa tahun terakhir, drone telah memberikan banyak manfaat yang belum pernah terjadi sebelumnya, terutama di sektor-sektor tertentu seperti sektor industri kreatif yang berhubungan dengan fotografi udara dan pembuatan film. Industri film yang juga merupakan keterkaitan antara bisnis dan teknologi yang dalam konteks komunikasi dikenal sebagai "media" (Permana, Puspitasari, and Indriani 2019), tak luput dari penggunaan drone yang dapat memberikan pengurangan biaya yang cukup signifikan dibandingkan dengan cara lama yaitu menyewa helikopter asli.

Penggunaan drone telah merevolusi cara pembuatan film saat ini. Bidikan sinematik yang mahal atau mustahil secara teknis sekarang menjadi kenyataan. Satu-satunya batasan adalah imajinasi pembuat film itu sendiri. Mathew Biro, seorang profesor seni modern dan kontemporer dari University of Michigan, mengatakan bahwa Drone akan melepaskan kita dari cara berpikir seni tradisional dan perpektif Renaissance serta membawa keluar dari tubuh kita dengan cara tertentu, semacam memberi kita perspektif overlay (Zacharek 2018b). Hal ini bukan hanya soal mendapatkan teknologi baru dan kesempatan menggunakannya, tetapi tentang emosi yang disampaikan melalui visual yang dibuat. Drone sebagai modernitas perspektif udara dapat dianggap sebagai suatu studi yang menambah karya penting dari dialektika teknologi modern, kultur dan pengalaman.

Teknologi drone juga akan memberikan pengaruh pada masyarakat di sektor penjualan, dan tren ini akan terus berlanjut selama beberapa dekade mendatang. Menurut Sachs, total penjualan yang akan dicapai oleh industri drone sebelum 2020 sebesar USD 100 Miliar. Sektor militer akan menjadi pasar penjualan terbesar untuk peralatan ini, tetapi peningkatan paling tajam akan datang dari sektor bisnis dan sipil, yang diharapkan tumbuh meningkat lebih dari 15\% per tahun (Santamarina and Segarra 2018).

Pada awalnya ketika orang kebanyakan mendengar kata 'drone', sebagian mengaitkannya dengan militer, juga berpikir tentang akan hadirnya musuh. Dalam perkembangannya, kemampuan untuk memasang kamera di pesawat nirawak tidak hanya menjadi anugerah untuk industri militer, namun juga menjadi revolusi bagi pencipta film terutama dari sisi tahapan terpenting di dalam proses produksi yaitu sudut pandang pengambilan gambar (Lestari and Yusanto 2019). Kata "drone" sendiri muncul setelah Perang Dunia pertama, Saat Angkatan Laut 
Kerajaan Inggris mengembangkan sejumlah pesawat tanpa awak dan pada tahun 1935 dibuatlah pesawat tanpa awak yang diberi nama "DH.82B Queen Bee" atau yang berarti ratu lebah. Kemudian angkatan laut menjuluki pesawat tanpa awak itu dengan istilah "drone" yang berarti lebah jantan.

Evolusi teknologi mempengaruhi pengembangan pesawat tanpa awak, sehingga mencapai desain yang kompleks selama bertahun-tahun, evolusi tergambarkan melalui Gambar 2. Tujuan dari artikel ini yaitu untuk mengetahui sejumlah peristiwa penting dalam evolusi kendaraan udara tanpa awak (drone) dimulai dari gagasan manusia untuk bisa terbang seperti burung hingga berkembang secara dramatis saat memasuki abad ke-21 untuk menciptakan berbagai perspektif udara sebagai bahasa visual.

Berdasarkan kajian literatur yang telah diperiksa, kajian sebelumnya dilakukan oleh beberapa penulis dilakukan dengan fokus penelitian pada perkembangan drone bersenjata untuk kebutuhan militer dengan fungsi utama untuk pengawasan (Afxentiou 2018) (Greene, D 2015) (Serle 2014) (Satia 2014), sementara penelitian tentang sejarah bagaimana drone berkembang untuk sektor lain, terutama di bidang sinema belum ada yang menjelaskan secara rinci dan kronologis.

Sejarah mencatat, sejumlah peristiwa penting dalam evolusi kendaraan udara tanpa awak (drone) dimulai dari gagasan manusia untuk terbang hingga memasuki abad ke-

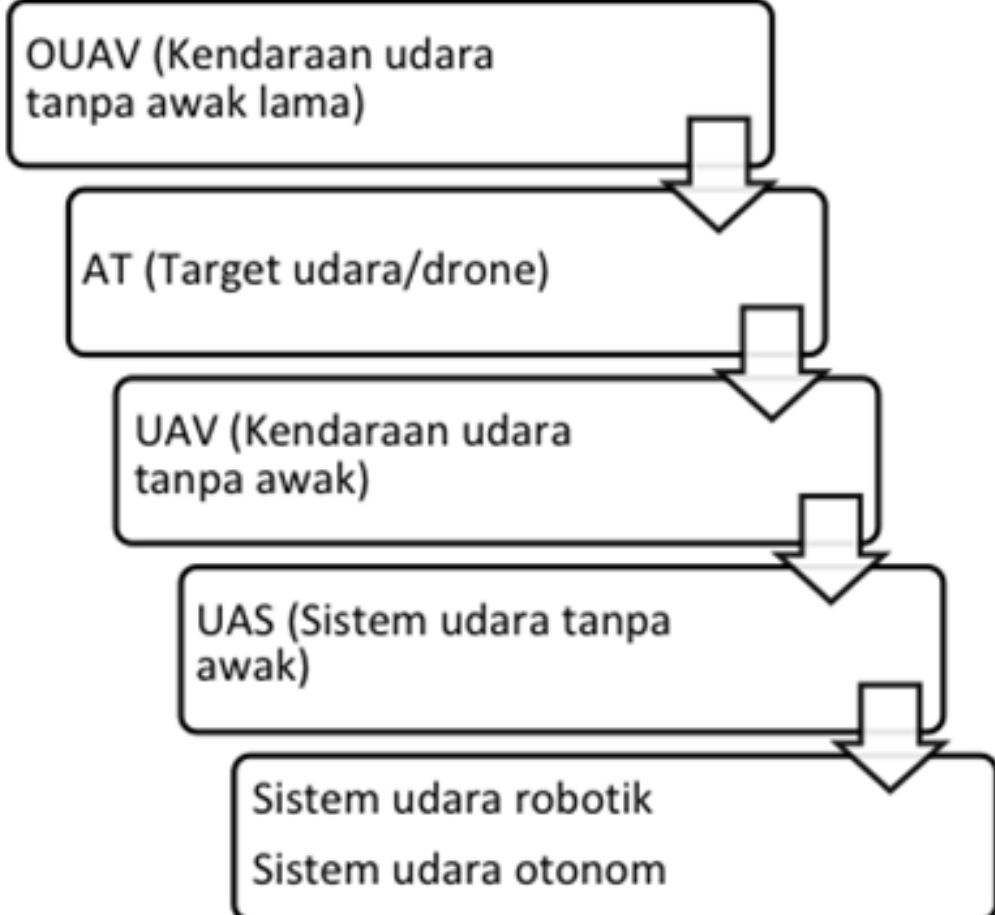

Sumber: Olahan Peneliti, 2020 
21 akan ditulis dalam artikel ini. Artikel ini bertujuan untuk mencatat perjalanan historis kendaraan udara nirawak secara berurutan yang dimulai dari gagasan manusia untuk terbang hingga berkembang untuk menciptakan berbagai perspektif udara sebagai bahasa visual.

\section{METODE PENELITIAN}

Penelitian ini ditulis dengan menggunakan pendekatan sinkronik dan diakronik, penelitian historis dapat melahirkan landasan konseptual seperti yang pernah diteliti oleh Tim Hatcher (Hatcher 2013). Sinkronik artinya bersama atau bertepatan menurut waktu; sedangkan diakroni adalah peninjauan historis, menurut pandangan yang lepas dari perspektif historis; Saussere menekankan pendekatan "Sinkronis" tentang bahasa bahwa dalam penelitian harus mendahulukan penyelidikan sinkronis, karena sistem dimana unsur bahasa berfungsi atau dipakai, lebih penting daripada mempelajari perkembangan unsur-unsur bahasa. Pentingnya nilai spontanitas dan sistematis lebih daripada nilai kerunutan (Matius 2017). Selain itu, penulisan melalui metode historiografi dapat menginformasikan situasi saat ini, dan juga dapat memengaruhi jalannya peristiwa, baik saat ini maupun di masa yang akan datang melalui proses rekonstruksi (Lockyear 1984).

Sejarah setidaknya dalam konteks gagasan historiografi dari sejarawan secara umum didefinisikan sebagai unit yang terdiri dari faktafakta ideografis (Jäger \& Rüsen, 1992), Heinz von Foerster mengingatkan bahwa apa yang disebut fakta secara otomatis menimbulkan keraguan. Dalam pertimbangannya, sejarah adalah proses evolusi interpretasi yang berkelanjutan: "Sejarah bergulir dan berbeda, berbeda, berbeda dan berbeda" ujarnya (von et al. 1997).

Dalam penelitian ini, penulis menganalisis dan memilih berbagai sumber, baik primer maupun sekunder, dari berbagai sumber pustaka. Penelitian ini menggunakan metode historiografi karena memberikan cara bagi para peneliti untuk memahami aktor serta konteks tindakan. Setiap sumber diperiksa, dikonfirmasi, dan dianalisis untuk kesesuaian sebagai sumber yang telah dievaluasi (Handlin et al. 1970). Penelitian ini berupaya mencatat peristiwa penting dan memberinya kategorikategori dalam evolusi perkembangan drone.

\section{HASIL DAN PEMBAHASAN}

Pembahasan di dalam artikel ini diawali dengan sebuah mitologi yang terjadi pada drone, yakni uraian pada gagasan manusia untuk bisa terbang menyerupai burung di angkasa sambil mengepakan sayapnya yang mirip dengan figur drone sudah dilakukan sejak awal peradaban manusia itu sendiri (Kane and Vose 2007). Dalam literatur Yunani dan Romawi kuno telah 
ditemukan cerita mengenai upaya manusia untuk terbang, antara lain Phaeton, anak dari Apollo yang terbang di angkasa. Di zaman Mesir kuno, dikenal adanya Khensu yaitu Dewa bersayap sejak 1.000 tahun sebelum Masehi, demikian pula Chaerubim, banteng bersayap dengan kepala manusia dari Assyria. Di dalam mitologi Yunani, nama Icarus yang dikenal bisa terbang, namun karena terbang terlalu dekat dengan matahari menyebabkan sayapnya meleleh dan jatuh ke laut. Sedangkan di dalam cerita 1.001 malam, dikenal adanya karpet terbang atau the flying carpet. Di dalam cerita pewayangan, dikenal pula tokoh Gatot Kaca, seorang ksatria yang gagah berani dan bisa terbang. Dalam cerita Mahabrata, Keluarga Pandawa yang terdiri dari 5 bersaudara yaitu Yudistira, Bima, Arjuna dan si kembar Nakula dan Sadewa. Gatot Kaca adalah anak Bima, ksatria ke-2 yang dikenal sebagai ksatria yang teguh pada pendiriannya dengan postur tubuh yang tinggi besar karena gagah berani dan bisa terbang. Demikian pula dalam mitologi Yunani kuno, dikenal adanya Dewa Icarus yang memiliki sayap dan dapat terbang mengarungi angkasa.

Upaya manusia untuk bisa terbang terus berlanjut pada abad pertengahan masa setelah kelahiran Nabi Isa, tercatat antara lain Bladud, Raja Inggris pada tahun 863 SM mengalami patah leher pada waktu berupaya untuk terbang dengan menggunakan sayap yang terbuat dari bulu burung. Demikian pula Oliver, seorang Paderi dari Malnesury pada tahun 1065, menyiapkan sepasang sayap untuk bisa terbang, namun gagal dan ia menemui kematiannya. Seorang Philosop dan sekaligus seorang ilmuwan Inggris, Roger Bacon pada abad ke13 mengatakan bahwa pada dasarnya manusia akan bisa mewujudkan cita-citanya untuk dapat terbang, namun kiranya Tuhan belum memberikan ilmunya untuk bisa melaksanakan cita-cita itu (Kane and Vose 2007).

Pada awal abad ke-16, Leonardo da Vinci (1452 - 1519) seorang jenius dari Italia, merupakan ilmuwan terkemuka pada masa Renaissance yang pertama kali mempelajari anatomi burung dan menyelidiki bagaimana burung bisa terbang. Dialah yang pertama kali menulis teori tentang mekanisme terbang pada tahun 1505 . Ia juga merancang mesin terbang yang didasarkan pada struktur sayap kelelawar.

Kontribusi besar pertama terhadap evolusi drone yaitu penemuan mekanisme mesin yang bisa terbang terjadi pada masa Pythagoras dan dikaitkan dengan Archytas dari Tarantas, Italia selatan. Dia menerapkan serangkaian konsep geometrical, dengan demikian terciptalah UAV pertama pada $425 \mathrm{SM}$, berupa mesin berbentuk burung yang dapat terbang menggunakan sistem mesin yang diletakkan di bagian perutnya.

$$
\text { Pada tahun } 400 \text { SM, Cina telah }
$$


Sumber: Mediamatic, 1992

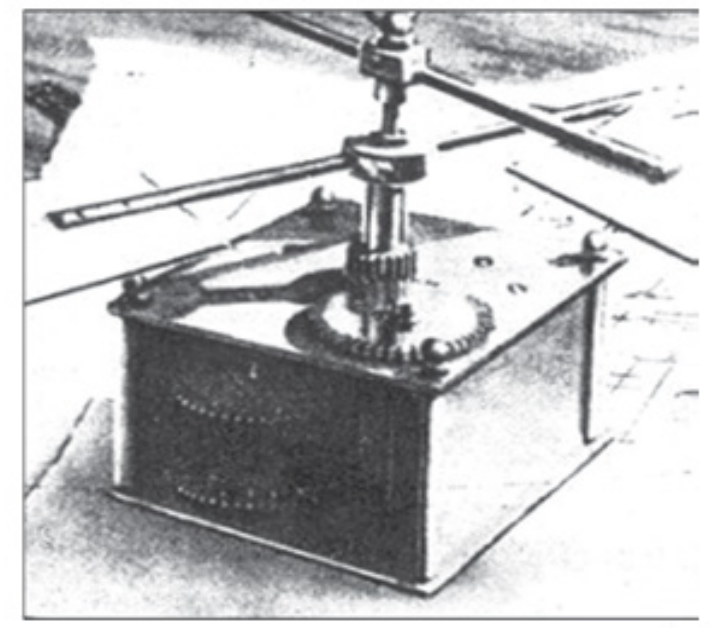

\section{Gambar 3 Drone pertama, Archytas of Tarantas}

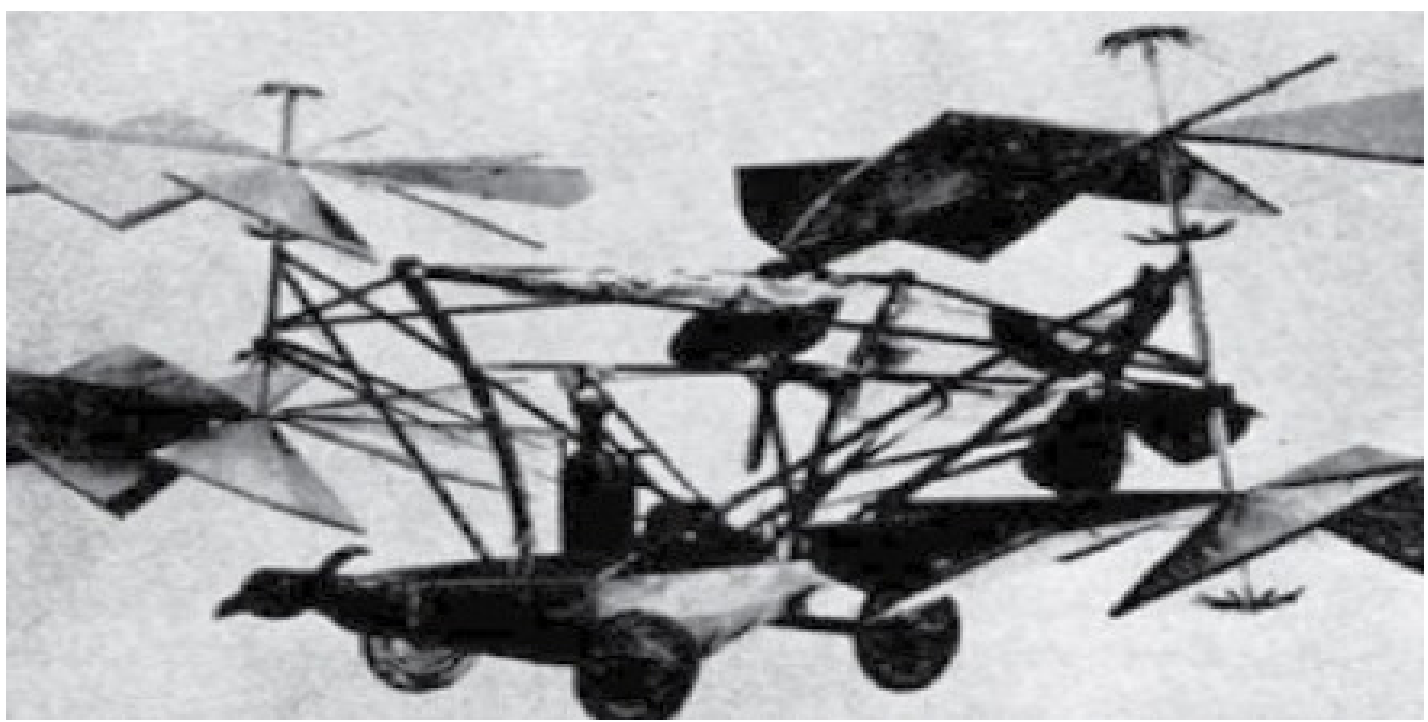

Sumber: Priscariu, 2017

\section{Gambar 4 Gerbong Convertoplan, G. Cayley}

mendokumentasikan gagasan tentang sebuah perangkat yang mencapai penerbangan vertikal. Leonardo da Vinci pada tahun 1483, merancang sebuah pesawat terbang yang mampu naik secara vertical, berdasarkan pertimbangan dari beberapa ahli sebagai gambaran helikopter di masa kini. Pada tahun 1508 da Vinci melanjutkan merancang sebuah baling-baling mesin yang mengandung mekanisme poros engkol ganda menggunakan kabel.
Kemudian pada tahun 1754, Mikhail Lomonosov merancang sebuah pendorong aksial, lalu pada 1783, George Cayley merancang sebuah gerbong convertaplane yang masih dalam bentuk gagasan karena pengukur sistem tenaga penggerak pada saat yang sama hanya tersedia untuk lokomotif uap. Pada tahun 1840, Horatio Phillips merancang sebuah mesin yang mampu menempuh rute penerbangan vertikal. Mesin ini mengandung 
ketel kecil untuk menghasilkan uap. Kemudian tahun 1860 Ponton d'Amecourt menerbangkan model helikopter yang lebih kecil dengan menggunakan uap.

Pada tanggal 5 Juni 1783, Montgolfier bersaudara dari Perancis melakukan percobaan penggunaan pertama balon udara yang berdiameter 35 kaki dan diisi dengan udara panas, berhasil mengudara setinggi 6000 kaki (1800m) dan terbang secara horisontal sejauh 7500 kaki. (Papilaya 2015). Pada percobaanpercobaan selanjutnya tepatnya pada tanggal 19 September 1783, balon udara berhasil mengangkut seekor domba, seekor ayam dan seekor bebek, dan merupakan awal dari mesin terbang pertama yang dibuat oleh manusia yang bisa dikembangkan untuk transportasi udara.

Historiografi drone di dunia militer dimulai tahun 1849. Tahun 1849 merupakan kali pertama penggunaan kendaraan tempur udara tanpa awak yakni saat Austria menyerang kota Venice menggunakan 200 balon tanpa pilot yang terisi bom serta dilengkapi oleh perangkat waktu. Kemudian pada tahun 1900, Nikola Tesla (1856-1943) menghadirkan konsep kontrol balon nirkabel dan pada tahun 1915 terjadi pertempuran udara kendaraan udara nirawak.

Sejarah tertulis tentang drone atau kendaraan tanpa awak yang dikembangkan untuk keperluan militer oleh negara Jerman pada saat pecahnya Perang Dunia ke-I.
Pemakaian balon udara sebagai pesawat pembom berhasil dieksekusi dengan baik pada tanggal 8 September 1915 untuk menjatuhkan bom di atas kota London.

Pada tahun 1916, terjadi upaya untuk menggunakan kendaraan udara nirawak yang dikenal dengan sebutan "target udara" oleh Archiband Montgomery Low (1888-1956), target dikendalikan dari darat oleh HewittSperry secara otomatis yang terintentegrasi dalam kontrol jarak jauh terhadap pesawat nirawak. Peristiwa ini dikenal dengan sebutan "bom melayang".

Pada November 1917 pesawat Bug Kettering dikenal juga sebagai "Kettering Aerial Torpedo" terbang dalam mode otomatis sebagai representasi dari pasukan Amerika Serikat, Pengembangan Bug Kettering dimulai pada April 2017 di Daytoh, Ohio setelah angkatan darat AS meminta Charles F Kettering untuk merancang bom tanpa awak dengan jangkauan 40 mil. Akhirnya Kettering bersedia mengumpulkan timnya, termasuk didalamnya Orville Wright. Pada tahun 1917, setelah konversi pesawat perang terjadi, Tipe standar E-1 dikukuhkan untuk drone.

Pada Juni 1944, Jerman menggunakan drone tipe Fi-103 selama Perang Dunia II, yang diketahui sebagai rudal jelajah. Setelah sekutu mendarat di Normandia, Jerman melepaskan Bom udara V-1 ke London. Pada akhir perang 
dunia ke-2, hamper 10.000 senjata telah diluncurkan untuk Inggris, Senjata itu adalah bom tanpa pilot pertama yang digunakan untuk perang. Pada bulan Oktober 1944, misi tempur pertama dan penggunaan UAV dilakukan dari pulau Balla, Jepang. Diledakkan oleh 10 bom di atas kapal TDR-1 yang dibuat oleh Interstate Aircraft Company di Los Angeles milik Angkatan laut AS. Lalu pada tahun 1944 diadakan proyek Aphrodite, sebuah program yang mengkonversi US B-17 dan PBY-4Y menjadi drone yang terbang dengan membawa bom. Proyek ini kemudian digunakan untuk uji nuklir dalam misi klasik bernama "dirty".

Selama perang dingin, pesawat pengintai tak berawak mulai memainkan peran penting dalam mengatur taktik dan strategi militer. Setelah perang Yom Kippur pada tahun 1973 industri Tadiran Israel mengembangkan Mastiff UAV untuk membantu pasukan darat memberikan informasi lewat pandangan udara. Industri pesawat Israel mulai menguji pesawat tak berawak mereka sendiri, drone yang dihasilkan bernama IAI Scout yang digunakan selama perang Lebanon pada tahun 1982. Scouts digunakan sebagai pengintai pasukan Hezbollah di Lembah Bekaa, Israel juga menggunakan drone sebagai umpan untuk memicu sistem anti pesawat Hizbullah serta membuka jalur aman untuk pesawat berawak. Pada tahun 1986, Industri pesawat Terbang
Israel bekerja sama dengan AAI Corporation mengembangkan RQ-2 Pioneer, sebuah pesawat pengintai modern pertama yang digunakan oleh militer Amerika; AS menggunakan pesawat pengintai ini dalam perang teluk pertama dan mempertahankannya hingga 2007.

Pada bulan April 1946, pesawat tanpa awak terbang pertama kali untuk melakukan penelitian ilmiah. Jenis drone yang digunakan dalam proyek ini yaitu Northrop P-61 Black Widow, berfungsi untuk mengumpulkan data cuaca dan angin di wilayah Amerika Serikat. Pada 1951, mesin jet pertama kali digunakan, proyek ini diberi nama Teledyne Ryan Firebee tipe I. Kemudian pada tahun 1955, terjadi penerbangan pertama pesawat tanpa awak untuk mengintai pesawat radio. Northrop SD-1 Falconer, kemudian digunakan oleh Angkatan tentara Amerika Serikat dan perusahaan Inggris, Beechcraft.

Pada tahun 1959, penerbangan tak berawak diberi nama UAV ((Unmanned Aerial Vehicle), saat ini populer dengan sebutan drone. Kemudian pada Tahun 1960, dilakukan peluncuran program UAV dengan nama kode "Red Wagon", lalu pada bulan Agustus tahun yang sama terjadi penerbangan pertama helikopter Gyrodine QH-50A tanpa awak di Maryland (Vasile 2017).

Pada bulan Agustus 1964, Angkatan Laut AS dan Angkatan Laut Vietnam Utara 
terlibat konflik drone di Teluk Tonkin AS. Sejak 1964 hingga jatuhnya Saigon pada tahun 1975, Strategic Reconnaissance Wing 100 3435 meluncurkan drone untuk melakukan pengintaian di Vietnam Utara akan tetapi dalam misi ini mereka kehilangan 554 kendaraan udara tak berawak.

Pada tahun 1966 proyek Lone Eagle yang juga disebut proyek Compass Arrow memprakarsai misi pengintaian yang dilakukan drone ke Cina, sehingga muncul D-21 yang diluncurkan oleh Angkatan Udara AS. Dengan tujuan untuk melakukan misi pengintaian foto di ketinggian tinggi.

Saat drone memasuki pusaran militer, Wall dan Monahan menulis Drone adalah "sebuah prisma untuk membuat teori tentang politik teknologi peperangan suatu pemerintahan" (Greene, D 2015). Drone melihat kehidupan manusia melalui kalkulasi target, dan lintasannya memperlihatkan logika Perang Global Melawan Teror yang berkembang ke medan perang. Produksi budaya drone-sentris kemudian menjadi provokasi politik, terhadap suatu tuntutan untuk melihat dunia seperti apa yang dilihat drone, lantas memunculkan pertanyaan bagaimana dan mengapa mereka melakukannya?

Dalam penelitian yang dilakukan oleh Daniel Green dari University of Marylan pada tahun 2015 menyatakan bahwa Amerika Serikat sedang melakukan kampanye untuk melacak target pengintaian secara global menggunakan kendaraan udara nirawak (Unmanned Aerial Vehicle), atau yang biasa disebut 'drone'. Pemerintahan Obama menggunakan dua pembenaran utama untuk memulai peperangan menggunakan drone: pertama: mandat dari global Otorisasi Angkatan Udara (AUMF) pada tahun 2001 untuk memburu ancaman teroris terhadap AS, dan kedua; kendala situasional dalam mengejar target spesifik di daerah terpencil di luar kendali pemerintah negara bagian dan sejumlah misi yang berada di luar jangkauan manusia (Greene, D 2015). Penelitian Satia melanjutkan apa yang telah diteliti Greene, ia menyebutkan bahwa selama masa kepresidenan George W. Bush, Menteri Pertahanan Robert Gates meluncurkan program rahasia yang menempatkan ratusan pesawat pengintai dan serangan tak berawak ke langit Irak, Afghanistan dan Pakistan. Pada saat itu, penggunaan drone meningkat secara tajam, yakni saat Barack Obama menjabat sebagai presiden (Satia 2014).

Drone gaya modern pertama kali muncul pada tahun 1980-an, ketika insinyur Israel mengembangkan model yang dilengkapi dengan kamera video. AS segera mengadopsi teknologi serupa dengan membuat pesawat tak berawak yang dikendalikan dari jarak jauh untuk merekam tentara irak pada masa perang 
teluk pertama. Drone Predator ditemukan oleh insinyur kedirgantaraan Israel bernama Abraham "Abe" Karem yang meningkat penggunaannya selama perang Afghanistan dan Irak karena kemampuannya untuk berkeliaran di daerah-daerah sasaran dalam jangka waktu yang lama. Militer Amerika juga menggunakan drone yang lebih kecil dengan tipe RQ-Raven untuk memberikan pandangan bagi prajurit atas bahaya yang akan terjadi.

Tahun 2013, Presiden Obama menyatakan tentang perang menggunakan pesawat nirawak, merupakan suatu taktikyang tepat dan diterapkan secara cerdas dan proporsional, dengan risiko korban sipil atau serangan balik yang lebih rendah dibandingkan dengan serangan udara konvensional atau misi oleh manusia. Sebelum serangan 9/11, drone sebagian besar digunakan untuk pengawasan dan digunakan dengan hemat, sehingga tidak berisiko melanggar kedaulatan nasional (Greene, D 2015). Sebelum serangan 9/11, drone sebagian besar digunakan untuk pengawasan dan digunakan dengan hemat, sehingga tidak berisiko melanggar kedaulatan nasional. Di awal kampanye Afghanistan, pembunuhan yang ditargetkan sebagian besar masih dilakukan oleh tentara black-ops Amerika atau perantara lokal. Pemerintahan Bush secara bertahap meningkatkan penggunaan drone dalam pengawasan dan serangan pada target bernilai tinggi (Scahill, Jeremy and Greenwald,
2014). Terutama setelah pemilihan Presiden Barack Obama, beban kerja ini dipindahkan ke pesawat nirawak. Salah satu daya tarik utama dari teknologi ini adalah kemampuan mereka untuk beralih dari peran Intelijen, Pengintaian, dan Pengintaian ke peran pemburu-pembunuh sebagaimana yang diperlukan dalam sebuah operasi.

Pada 2 Mei 2013, Angkatan Laut AS mengumumkan skuadron pertama yang mengikutsertakan pesawat tak berawak yang dapat dikendalikan dari jarak jauh. Penempatan pertama skuadron itu dinamai "The Magicians", Skuadron ini akan terdiri dari delapan seahawk MH-60R dan 10 MQ-8B Fire Scouts. Lalu pada Selasa, 14 Mei 2013Angkat laut AS menorehkan sejarah dengan meluncurkan jet tak berawak dari kapal induk untuk pertama kalinya. Drone siluman tipe X-47B lepas landas pada pukul 11.18 pagi dari kapal George W. Bush di Samudera Atlantik. Peluncuran sukses X-47B adalah titik awal dalam sejarah tentang bagaimana kita akan mengintegrasikan pesawat tak berawak di geladak penerbangan kapal induk di masa depan," tulis Laksamana Mat Winter di situs resmi Angkatan Laut AS. Dengan jangkauan 2.000 mil laut, jet tak berawak seperti $\mathrm{X}-47 \mathrm{~B}$ ini bisa memberikan angkatan laut serangan dari jarak jauh dan kemampuan pengintaian.

Pemerintahan Bush secara bertahap 
meningkatkan penggunaan drone dalam pengawasan dan serangan pada target yang bernilai tinggi (Scahill, Jeremy 2013). Terutama setelah pemilihan Presiden Barack Obama, beban kerja ini dipindahkan ke pesawat nirawak. Salah satu daya tarik utama dari teknologi ini adalah kemampuan mereka untuk beralih dari peran Intelijen dan pengintaian ke peran pemburu sebagaimana yang diperlukan dalam sebuah operasi. Setidaknya 59 operator bekerja sama untuk meluncurkan sepasang drone, dari pangkalan militer yang ada di Afghanistan setelah invasi pada tahun 2001, atau pangkalan CIA di Pakistan yang diambil setelah Al Qaeda melarikan diri dari Afghanistan ke Waziristan (Scahill, Jeremy and Greenwald, 2014). Jenis drone tersebut berwarna abu-abu bernama MQ-1 Predators, memiliki panjang 8,2 meter dan lebar sayap 14,3 meter, beratnya tidak kurang dari dua ton, baling-baling yang ditenagai mesin bernama Rotax dari Austria, dukungan ini memungkinkan drone mencapai ketinggian jelajah kurang lebih 4.500 meter hingga 14 jam. Dalam perkembangannya, drone jenis MQ mampu terbang lebih dari 40 jam dan terbang sejauh 1.200 mil, termasuk Jenderal Iran Qasem Soelaemani tewas dirudal oleh drone MQ-9 Reaper pada awal Januari lalu. Angkatan udara AS menghasilkan lulusan pertama untuk program General Atomics MQ-9 Reaper Training Pilot yang merupakan bidang karir baru UAV operator untuk menerbangkan pesawat tanpa awak pada 22 September 2012 (Garrett 2019a).

Di Pakistan sendiri, CIA saat berada di bawah pemerintahan Bush. meluncurkan 51 serangan drone antara tahun 2004 sampai 2009 (Elaine 2011), sementara itu CIA saat berada di bawah pemerintahan Obama meluncurkan 339 serangan drone antara tahun 2009 sampai 2014 (Serle 2014).

Negara China pada 25 November 2013 mengumumkan uji coba drone "Killer" siluman pertamanya yang diberi nama Lijian yang berarti pedang tajam. Drone ini mirip dengan drone $\mathrm{X}-47 \mathrm{~B}$ yang sedang diuji oleh Angkatan Laut AS. 2013 juga disebut sebagai tahun besar untuk UAV, 2013 dianggap tahun dimana masyarakat mulai memahami UAV bukan hanya pesawat tempur tanpa awak yang dipergunakan oleh militer, tetapi dapat membentuk kembali perdagangan dan transportasi bahkan etika. Enam acara besar berlangsung pada 2013, diantaranya Amazon yang menyatakan rencananya untuk memulai paket pengiriman dengan perantara drone untuk target lima tahun kedepan, Washington pun mulai mengerjakan regulasi drone.

Dalam artikelnya, Afxentiou menyimpulkan bahwa penempatan drone untuk kebutuhan militer, secara efektif mereproduksi kondisi historis dan substansial dari kekerasan 
teroris. Gagasan bahwa drone mengubah kekuatan udara menjadi pembunuhan target individu dan selektif, bukanlah pencapaian inovasi teknologi (Afxentiou 2018).

Purwarupa drone militer pertama Indonesia, Elang Hitam diperkenalkan di akhir Desember, tahun 2019 lalu. Pesawat udara nirawak yang dikembangkan oleh Konsorsium Pesawat Terbang Tanpa Awak ini mampu terbang tanpa henti selama lebih 24 jam dengan ketinggian jelajah hingga 23.000 kaki. Selain itu, Drone buatan Indonesia lainnya dengan tipe Light (PUNA) yang dibuat oleh BPPT (Badan Pengkajian dan Penerapan teknologi) untuk aplikasi penginderaan jauh dan pemetaan telah disertifikasi sebagai produk militer pada akhir 2018.

Militer seakan telah menjadi katalisator selama bertahun-tahun untuk pengembangan teknologi UAV, yang memungkinkan drone menjadi komersial serta lebih murah, lebih ringan, dan lebih canggih. Pandangan udara menggunakan pesawat nirawak menyatukan penerbangan dengan sinematografi. Hal ini dimungkinkan oleh ketersediaan kamera kecil beresolusi tinggi yang portabel, ringan, dan terjangkau. Karakteristik ini membuat kamera dapat dipasangkan pada drone, memungkinkannya untuk terbang rendah maupun tinggi serta mampu merekam dari sudut pandang udara.
Sebelum masuk ke sinema, pandangan udara yang dihasilkan drone merujuk dari adanya fotografi udara. Selama ratusan tahun, perspektif udara telah membuat gambar-gambar menakjubkan tentang planet bumi ini. Mulai dari mengungkapkan skala bencana alam yang terjadi, hingga memperkirakan skala dalam sebuah pertempuran.

Menurut kajian Paula Amad pada tahun 2012 tentang sejarah fotografi udara yang diterbitkan di Jurnal History of Photography, Fotografi udara pertama kali diambil ada tahun 1858 oleh Gasper Felix Tournachon, dikenal juga sebagai "Nadar". Foto itu diambil dari balon udara pada ketinggian 1200 kaki di atas kota Paris (Amad 2012).

Tahun 1860, James Wallace Black mengambil foto udara kota Boston dengan menggunakan balon udara diatas ketinggian 2000 kaki. Foto James ini dianulir sebagai foto udara tertua yang mampu bertahan. Pada tahun 1889, Arthur Batut mengambil foto udara dari Labruguiere, Perancis, menggunakan sebuah layangan. Kemudian pada 1903, Bavarian Pigeon Corps menggunakan merpati untuk mengambil foto udara. Dengan cara kamera kecil yang ringan diikatkan pada merpati sebelum mereka terbang. Lalu kamera disetel untuk menangkap gambar secara otomatis setiap 30 detik. Waktu itu, teknik ini dianggap sebagai cara yang inovatif dalam mengambil 
foto udara dibandingkan dengan menggunakan balon udara yang dianggap berbahaya dan layangan yang tidak stabil (Hemphill 2006).

Pada 1906, Insinyur Jerman Alfred Maul, mengambil foto udara menggunakan sebuah roket yang didorong oleh kompresi udara, dari ketinggian 2600 kaki yang dicapai hanya dalam delapan detik, kamera dikeluarkan dari roket dan mendarat menggunakan parasut. Pada tahun yang sama, seorang apoteker Jerman Julius Neubronner menerapkan metode fotografi udara dengan mengikat kamera ke burung-burungnya. Kemudian saat terjadi Perang Dunia I, fotografi udara menjadi dikenal sebagai alat operasional militer. Pesawat digunakan untuk mendapatkan foto dari pergerakan dan teritori musuh. Penggunaan foto udara dengan cepat berkembang selama perang dengan digunakannya pesawat pengintai yang dilengkapi dengan kamera untuk merekam gerakan dan pertahanan musuh. Pada awal konflik, kegunaan foto udara tidak sepenuhnya dirasa penting, sampai berhasil dilakukan pengintaian dengan membuat peta sketsa dari udara. Kamera dilengkapi pada semua jenis pesawat, dan praktik pengintaian udara di masa perang lahir untuk mengungkapkan gerakan musuh atau merencanakan serangan di masa depan.

Setelah perang selesai, potensi penggunaan teknologi ini untuk keperluan sipil diakui.
Teknologi ini mulai digunakan untuk membuat map, mengambil informasi mengenai topografi, bentuk lahan, vegetasi, dan fitur budaya yang hadir di permukaan bumi. Semenjak itu, banyak negara telah memotret kawasan mereka secara teratur, untuk keperluan militer maupun sipil. Hanya beberapa tahun setelah penerbangan pertama dilakukan oleh Wright bersaudara di Kitty Hawk, pada tahun 1903 sinematografer L.P Bonvillian memotret landskap Le mans, Prancis dari pesawat terbang yang dikemudikan oleh Wilbur Wright sendiri.

Kemudian George Lawrence, seorang fotografer dari Illinois mengeksplorasi metode pengambilan panorama dengan mengikat kamera film format besar di layang-layang. Foto paling terkenalnya merekam kerusakan yang yang disebabkan oleh gempa bumi dan kebakaran di San Pransisco pada tahun 1906. Lawrence menggunakan 17 layang-layang untuk menerbangkan kamera diatas ketinggian 2.000 kaki untuk merekam peristiwa tersebut. Disinyalir foto-foto yang dihasilkan Lawrence adalah yang paling pertama sebagai foto udara yang dijadikan berita.

Frederick Charles Victor Laws mulai percobaan foto udara pada tahun 1912 melalui penggunaan skuadron RAF no.1 dengan mengambil foto dari pesawat Inggris Beta. Ia menemukan bahwa foto artikel yang diambil secara tumpang tindih $60 \%$ dapat digunakan 
untuk menciptakan efek stereokospik bila dilihat dengan stereoscope sehingga menciptakan persepsi kedalaman yang bisa membantu dalam kartografi dan keperluan intelijen dengan menggunakan foto udara. Pilot-pilot pengintai The Royal Flying Corps mulai menggunakan kamera untuk merekam pengamatan mereka pada tahun 1914 dan di pertempuran Neuve Chapelle. Pada tahun 1915 seluruh sistem parit sebagai pertahanan Jerman sudah terekam oleh kamera.

Kamera udara pertama tercatat diciptakan oleh Kapten John Moore-brabazon pada tahun 1915 dengan bantuan dari perusahaan Thornton-Pickard, yang ternyata sangat meningkatkan efisiensi pembuatan foto udara. Kamera dimasukan ke lantai pesawat dan memungkinkan pilot bisa merekam dengan interval.

Tahun 1916, Austro-Hungarian Monarchy membuat foto udara di atas Italia dengan sudut pandang kamera vertikal untuk pembuatan peta. Foto udara yang dibuat oleh Cotton waktu itu dianggap sangat maju. Ia merintis teknik memotret dari tempat tinggi dengan teknik fotografi strereoskopik kecepatan tinggi yang berperan dalam mengungkapkan target penting lokasi sasaran untuk kebutuhan militer dan intelijen.

Memasuki perang dunia ke-2, Pada tahun 1939, Sidney Cotton dan Maurice LongBottom adalah orang pertama yang menyarankan agar pengintaian udara lebih cocok dilakukan oleh pesawat kecil yang cepat serta mampu terbang tinggi agar terhindar dari deteksi dan intersepsi. Meskipun hal ini tampak wajar sekarang. Tugas-tugas pengintaian modern yang dilakukan dengan pesawat cepat dan mampu terbang tinggi, pada saat itu merupakan ide yang radikal. Selama Perang Dunia ke-II, Fotografer Margaret Bourke-White menjadi wanita pertama yang terbang dengan jet tempur AS di atas tanah musuh saat ia meliput serangan AS di Tunis.

Pada akhir perang, kamera udara telah berkembang secara dramatis dengan bertambahnya ukuran dan kedalaman fokus. Fotografi udara semakin sering digunakan karena terbukti penting untuk kebutuhan militer; kedua belah pihak yang berperang telah memotret dua kali sehari seluruh medan perang dan telah mengambil lebih dari setengah juta foto sejak awal perang. Akhir dari perang dunia II dan munculnya perang dingin membawa kemajuan lebih berarti pada fotografi udara, terutama berkat Space Race. Foto pertama yang diambil dari luar angkasa pada tanggal 24 Oktober 1946 yang menggambarkan sekilas bumi.

Dengan kemajuan teknologi, satelit kemudian digunakan untuk mendapatkan data fotografi dengan kualitas baik. Fotografi satelit 
bumi pertama dibuat pada 1 April 1960, oleh satelit cuaca bernama TIROS-1. Pada tahun yang sama, Amerika Serikat mulai mengumpulkan fotografi intelijen bumi menggunakan Corona, yang merupakan satelit pengintai. Saat ini, telah terdapat banyak satelit yang diluncurkan untuk berbagai keperluan. Beberapa dari mereka digunakan untuk perkiraan cuaca, siaran, dan menciptakan penemuan atau teknologi baru.

Tahun 2005, McFayden memulai cara lain ketika dia memiliki ide brilian untuk menggunakan drone dalam mengambil foto udara. Lain lagi dengan foto-foto yang dihasilkan seorang fotografer dan sutradara Reuben wu dari Inggris, Wu telah menciptakan serangkaian foto landskap yang diterangi oleh drone yang dimodifikasi khusus. Terinspirasi oleh lukisan romantis abad ke-19 perihal fiksi ilmiah dan gagasan eksplorasi antar planet. Hasilnya menampilkan nada-nada warna surealis sekaligus naturalistik. Foto yang dihasilkan seperti suatu tempat yang biasa dikunjungi dalam kehidupan nyata, meskipun aslinya tidak akan terlihat seperti yang ada di dalam foto tersebut. Eksplorasi pencahayaan dari drone yang dibuat oleh $\mathrm{Wu}$ menjadikan dunia nyata seakan mimpi-mimpi yang dinyatakan dalam bahasa visual.

Di negara Indonesia sendiri, fotografi udara menggunakan drone pertama kali dipublikasikan dalam headline Kompas pada tanggal 5 Juli 2016, Foto tentang kampanye Jokowi itu diambil dengan menggunakan tipe drone DJI Phantom 2 dengan kamera GoPro. Drone yang merupakan sebuah alat yang hanya dapat dioperasikan oleh manusia, seakan memberitahu kita apa yang menarik secara visual. Seperti alat apapun yang digunakan oleh manusia; pensil, kuas atau kumpulan aksara yang berbentuk puisi. Karena itu semakin banyak drone ditujukan untuk dunia seni.

Pembuatan film lewat pandangan udara terjadi pada perang dunia pertama dan perang dunia kedua, fenomena ini juga dipopulerkan pada tahun 1950-an dan 1960-an oleh perfilman Hollywood yaitu film The Birds (1963) dan The Sound of Music (1965). Gambar yang diambil dari helikopter menjadi populer sebagai gambar dasar atau gambar yang digunakan untuk bagian judul pembuka film seperti yang ada di film The Shining (1980) karya Stanley Kubrick atau Jurassic Park (1993) karya Steven Spielberg.

\section{Menurut Wilbur Wright und seine} Flugmaschine, penggunaan pertama kamera film yang dipasang pada pesawat udara adalah pada tanggal 24 April 1909 di atas kota Roma dengan menggunakan film bisu pendek selama 3:28 menit. Begitu juga dalam tesisnya, Gibb menulis salah satu jurnalis pertama yang menggunakan drone dilengkapi kamera untuk merekam video dampak dari tornado keras EF4 yang meluluh lantakan Tuscaloosa, Ala, pada 
bulan April 2011 adalah jurnalis foto lepas dan produser untuk CNN, Aaron Brodie (Gibb 2013). Adapun fotografi udara menggunakan pesawat tanpa awak atau drone dipopulerkan oleh Raphael "Trappy" Pirker pada tahun 2010 menjadi berita utama di AS karena menerbangkan drone yang dilengkapi kamera di atas patung Liberty, Jembatan Brooklyn, dan sebagian kota Manhattan. Rekaman gambar yang dihasilkannya telah menimbulkan diskusi mendalam soal keindahan perspektif udara (Gettinger et al. 2014).

Setiap munculnya teknologi baru cenderung menjadi lebih kecil dan lebih mudah diakses dari waktu ke waktu. Hal yang sama berlaku bagi untuk drone. Pada awal 2000-an, budaya produksi drone sendiri-sendiri mulai muncul dari komunitas pesawat kendali jarak jauh yang sudah lama ada. Forum online seperti drone DIY membantu pengguna untuk berbagi kiat satu sama lain. Perangkat keras dan perangkat lunak dikembangkan seperti auto pilot dan sistem pendeteksian dini untuk menghindari tabrakan, kamera beresolusi tinggi diterapkan pada drone yang menjadikan fotografi udara lebih mudah diterapkan daripada masa sebelumnya.

Pada tahun 2006, Frank Wang Tao seorang mahasiswa teknik dari Hongkong University of Sciences and Technology membangun sebuah perusahaan untuk memenuhi hasratnya terhadap helicopter yang bisa dikendalikan dari jarak jauh. Perusahaan tersebut diberi nama DJI, singkatan dari Da-Jiang Innovations untuk membuat pesawat nirawak untuk mengambil foto dan video. Sementara itu di Prancis, pada 5 januari 2010 Parrot AR Drone diluncurkan sebagai produk pertama untuk konsumen drone. Terobosan besar dilakukan Parrot dengan merilis drone yang dikendalikan smartphone Pada tahun 2012, DJI merilis flame wheel yang berfungsi sebagai kerangka atau badan drone, pada akhirnya DJI memutuskan untuk merilis UAV yang sudah dirakit sepenuhnya agar bisa bersaing di pasar komersial. Dengan demikian, Phantom seri pertama diluncurkan dengan kamera dan GPS yang sudah terintegrasi. Sejak saat itu kedua perusahaan telah mendominasi pasar konsumen, masing-masing telah menjual lebih dari 1 juta drone.

Saat ini DJI memiliki sekitar 70\% pangsa pasar konsumen drone. Pada bulan September 2016, Pabrik dari Amerika, Go Pro mengumumkan produk yang diberi nama "Karma". Ini adalah pesawat tanpa awak yang portable yang dirancang untuk bepergian. Tidak mau kalah, satu minggu kemudian DJI yang berbasis di provinsi Shenzen meluncurkan kembali drone portable yang bisa dilipat, lebih kecil, cepat dan mencakup fitur-fitur canggih bernama Mavic. Pada 1 Maret 2016, DJI pengembang UAV yang berbasis di China ini kembali meluncurkan produk terbarunya, 
quadcopter DJI Phantom 4 menggunakan beberapa kamera dan perangkat lunak untuk merasakan dan menghindari rintangan secara otomatis. Dengan menggunakan aplikasi seluler, operator dapat memilih tujuan dan drone akan memilih rute terbaik untuk sampai kesana, saat pesawat terbang, Pilot dapat fokus mengendalikan kamera tanpa khawatir tentang navigasi.

Historiografi drone hingga sinema. Pada awal abad kedua puluh, sebuah kelompok pembuat film dari Uni Soviet menuturkan bahwa kamera sebagai alat memiliki kapasitas mempersepsikan jauh di atas mata dan tubuh manusia. Ide awal 'the Kino-Eye' dari Uni Soviet ini sudah bertahan sebagai konsep pada teori film dan filosofi, jauh sebelum Marshall McLuhan membuat teori ekstensi tubuh sebagai kunci untuk memahami media massa (Binns 2019). Gambar yang diambil dari pesawat atau helikopter jelas mendemonstrasikan besarnya dan skala yang dapat diberikan oleh pengambilan udara. Penggunaan praktis dari drone nirawak pada tingkat konsumen telah membanjiri gambar udara di situs berbagi video, dan peningkatan drastis pada nilai produksi dari vlog dan video rumahan. Sinematografer juga sudah banyak menggunakan drone untuk mengambil pemandangan yang indah di seluruh lanskap atau melacak karakter maupun objek dari perspektif udara, mereka memanfaatkan aksesibiltas biaya atau harganya yang murah dan kemudahan penggunaan. Ada garis keturunan yang jelas di sini antara sinematografi drone dan fotografi udara, drone dengan ukurannya yang kecil dan kemampuan bermanuver dari drone memberikan kesempatan bagi sinematografer dan sutradara untuk bereksperimen.

Penggunaan drone telah memberi manfaat besar bagi industri film. Drone telah digunakan untuk pembuatan film sejak awal teknologi ini dikembangkan. Film yang menggunakan drone di Hollywood yaitu The Wolf of Wall Street pada 2013, film yang disutradarai Martin Scorsese ini merekam adegan pesta dari atas dengan menggunakan drone. kemudian pada 2014 The Expendables 3; Sebanyak tiga puluh Adegan dalam film The Expendables 3 menggunakan shot yang diambil dari drone, Tahun 2015 ada Chappie, juga Spectre dan Jurassic World, di Jurassic Wolrd yang diproduksi pada tahun 2015, kamera yang dipasang drone menukik rendah diantara kerumunan orang yang diserang seakan sudut pandang penonton diajak untuk meniru pergerakan reptil terbang, lalu pada tahun 2016 ada Captain America: Civil War (Flynn 2016).

Di Amerika, Pada tahun 2013 Drone mempengaruhi kebudayaan populer. Sineas memasukkan drone dalam film mereka, Seperti Oblivion, yang dibintangi Tom Cruise. Kemudian Film Zero Dark Thirty, yang bercerita 
tentang "perburuan terbesar dalam sejarah," ketika CIA mengejar Osama Bin Laden, yang menunjukkan drone dan lebih banyak lagi hal tentang drone (McKinnon 2014). Sebuah film pendek yang dirilis pada tahun 2014 berjudul Superman with Gopro diciptakan oleh sineas asal Los Angeles menggunakan drone DJI Phantom 2 mendapatkan views 23 juta di platform Youtube. Pada 9 Maret 2016, Phantom 2 memecahkan rekor ketinggian UAV dengan ketinggian 11.000 kaki. Karena sebenarnya quadcoptes DJI hanya dibatasi pada ketinggian maksimal 1.500 kaki. Dengan jarak tempuh ketinggian dicapai dalam tiga setengah menit UAV tersebut disiarkan melalui kanal youtube.

Pada tahun 2014, Badan penerbangan Amerika Serikat, Federal Aviation Administration (FAA), telah mengijinkan drone bekerja untuk industri perfilman Holyywood. Sky Fall adalah film yang pertama dari Film James Bond yang menggunakan drone. Rekaman udara berkecepatan tinggi yang direkam oleh drone dalam adegan awal film itu mampu membuat gebrakan di Hollywood, Film ini juga menerima Oscar pada tahun 2014 untuk kategori flying cam.

Dalam artikel yang ditulis Galvane dan Lino (2017) dengan judul "Directing Cinematographic Drones" mereka mengeksplorasi bentuk penyutradaraan film dengan perspektif sinematografi yang berbeda dengan menggunakan drone (Galvane et al. 2017). Kemudian pada tahun 2018, tim yang dipimpin Bonatti mengembangkan metode untuk membuat film dengan perspektif udara melalui bidikan drone yang diatur secara otomatis melalui sebuah aplikasi, yang menarik Bonatti mengadegankannya dengan aktor, mobil, dan sepeda manusia serta dikuti gerakan kamera yang berbeda dalam menghasilkan berbagai jenis shot (Bonatti et al. 2018).

Sejak tahun 2015, telah hadir produksi film yang sepenuhnya diambil menggunakan drone, Festival film drone pertama kali berlangsung di New York, ada pula festival film unik khusus drone, yaitu Flying Robot International Festival (FRIFF), yang merupakan perayaan sinematografi udara dengan memberikan hadiah besar dalam berbagai kategori. (Santamarina and Segarra 2018).

Di Indonesia drone mulai marak digunakan untuk kebutuhan pembuatan film pada tahun 2014. Film dokumenter dari Ekspedisi Indonesai Biru yang diproduksi oleh Watchdoc serta disutradarai oleh Dandhy Dwi Laksono sekaligus pilot drone pada tahun 2015 adalah salah satu film yang memanfaatkan drone dalam proses produksinya. Pada tahun 2015 pemerintah mengeluarkan regulasi tentang pengendalian pengoperasian system pesawat udara tanpa awak di ruang udara yang dilayani di Indonesia yang tertulis dalam Peraturan 
Menteri Perhubungan Republik Indonesia Nomor 180. Sebagai penutup, Ketika penulis membuat artikel ini berada dalam situasi pandemi covid-19, drone juga banyak digunakan untuk membantu aktivitas manusia dalam menggantikan perannya di kondisi yang penuh risiko, seperti melakukan penyemprotan desinfektan.

\section{SIMPULAN}

Setelah memeriksa historiografi pesawat nirawak atau drone dimulai dari munculnya gagasan manusia untuk melayang dan melambung tinggi seperti seekor burung ke langit di angkasa hingga terciptanya drone untuk militer hingga ke ranah sinema, penulis berkesimpulan bahwa drone adalah sinematografer posthumanisme yang sempurna, di dalamnya ada teknologi untuk terbang, kendali nirkabel, mengambil gambar, dan kecanggihan warna, semua itu menjadi perspektif baru terhadap dunia. Salah satu kunci untuk memahami bagaimana drone dapat menggeser perspektif manusia dengan menyakini bahwa drone tidak memiliki pikirannya sendiri, tetapi gerakannya mengikuti apa yang telah dipilih oleh operatornya, hal itu membuat telaah lebih lanjut tentang bagaimana terciptanya kosakata visual yang dinamis, mata melihat terhadap apa yang sudah dilewati dan direkam drone.

Pada akhirnya, drone mengajak kita berpikir lebih jauh dari hanya sekadar representasi, memberikan gambar hidup tentang realitas yang tidak bisa dijangkau oleh pandangan manusia pada umumnya.

\section{DAFTAR PUSTAKA}

Afxentiou, A. (2018). A history of drones: moral(e) bombing and state terrorism. Critical Studies on Terrorism 11(2):30120.

Amad, P. (2012). From god's-eye to cameraeye: aerial photography's post-humanist and neo-humanist visions of the world. History of Photography 36(1):66-86.

Elaine, P. (2011). The bush years: pakistan strikes $2004-2009$.

Binns. (2019). Dronopoetics: unmanned aerial cinematography and Ivan Sen's goldstone. Journal of Asia-Pacific Pop Culture 4(1):26.

Bonatti, R., Zhang, Y., Choudhury, S., Wang, W., and Scherer, S. (2018). Autonomous drone cinematographer: using artistic principles to create smooth, safe, occlusionfree trajectories for aerial filming. ArXiv:1808.09563 [Cs].

Flynn, S. (2016). Drones in movies: 7 Hollywood movies filmed with drones. Skytango. Retrieved April 28, 2020 (https://skytango.com/drones-in-movies-7hollywood-movies-filmed-with-drones/).

Galvane, Q., Lino, C., Christie, M., Fleureau, J., Servant, F., Tariolle, F. L., and Guillotel, P. (2017). Directing cinematographic drones. ArXiv:1712.04216 [Cs].

Garrett, L. (2019a). History timeline. History Timeline. Retrieved May 25, 2020 (http:// prod-staging.aiaa.org/about/History-and- 
Heritage/History-Timeline).

Gettinger, D., Michel, A. H., Pasternack, A., Koebler, J., Musgrave, S., and Rankin, J. (2014). The drone primer a compendium of the key issues.

Gibb, A. (2013). Droning the story.

Greene, D. (2015). Drone vision. Surveillance \& Society 13(2):233-49.

Handlin, O., A. M. Schlesinger, S. E. Morison, F. Merk, AM Schlesinger, and P. H. Jr and Buck. (1970). Harvard Guide to American History.

Hatcher, T. (2013). Robert Owen: a historiographic study of a pioneer of human resource development. European Journal of Training and Development 37(4):41431.

Hemphill, J. J. (2006). Pigeon aerial photographs. Retrieved February 4, 2020 (http://www.geog.ucsb.edu/ jeff/115a/ history/pigeonremotesensing.html).

Kane, R. M., and Vose, A. D. (2007). Air Transportation. Kendall/Hunt Pub. Co.

Lestari, Yunita, W., and Yusanto, F. (2019). Simbol illuminati dalam video klip. ProTVF 3(1):35.

Lockyear, R. (1984). Writing history: Roger Lockyear on writing historical biography. History Today 46-49.

Matius, A. (2017). Moving image theory. Sanggar Luxor.

McKinnon, G. D. (2014). The birth of a drone nation: American unmanned aerial vehicles since 1917. 118.

Papilaya, A. (2015). Drone foto \& videografi. Jakarta: Grasindo.

Permana, R. S. M., Puspitasari, L., and Indriani, S. S. (2019). Industri film Indonesia dalam perspektif sineas Komunitas Film Sumatera Utara. ProTVF 3(2):185.

Santamarina, V., and Segarra, M. (2018). Drones and the creative industry.

Satia, P. (2014). Drones: a history from the British Middle East. Humanity: An International Journal of Human Rights, Humanitarianism, and Development $5(1): 1-31$.

Scahill, J. (2013). Dirty wars: the world is a battlefield. New York: Nation Books.

Scahill, J., and Greenwald, G. (2014). The NSA's secret role in The U.S. Assassination program. HuffPost. Retrieved February 4, 2020 (https://www.huffpost.com/entry/thensas-secret-role-in-the-us-assassinationprogram_n_4759302).

Serle, J. (2014). Drone wars: the full data. The Bureau of Investigative Journalism. Retrieved February 4, 2020 (https:// www.thebureauinvestigates.com/ stories/2017-01-01/drone-wars-the-fulldata).

Vasile, P. (2017). The history and the evolution of UAVs from the beginning till the 70s. Journal of Defense Resources Management $8(1): 181+$.

von, Foerster, $\mathrm{H}$. $\mathrm{Mu}$ 1ler, $\mathrm{Mu}$ '1ler A. and K. H. (1997). U ber konstruktivismus und geschichte. ein gespra "ch (about constructivism and history: a conversation). Austrian Journal of the Science of History 8(1):127-40.

Zacharek, S. (2018b). How drones are revolutionizing the way film and television is made. Time. Retrieved May 26, 2020 (https://time.com/5295594/droneshollywood-artists/). 